
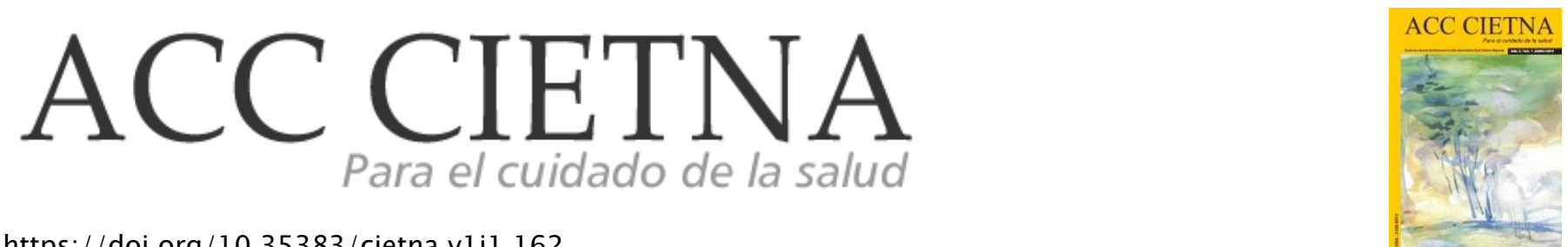

https://doi.org/10.35383/cietna.v1i1.162

\title{
Experiencias de las enfermeras al brindar cuidados integrales en el primer nivel de atención
}

\author{
Morales Pizarro Rossana ${ }^{1}$, Muro Excebio Iliana ${ }^{2}$
}

\begin{tabular}{l} 
INFORMACIÓN DEL ARTÍCULO \\
\hline Historia del artículo: \\
Recibido el 11 de mayo de 2013 \\
Aceptado el 15 de diciembre de 2013
\end{tabular}

Palabras claves:

Enfermera

Experiencias

Cuidado integral

Primer nivel de atención

\section{RESUMEN}

El objetivo fue describir y analizar las experiencias de las enfermeras al brindar cuidados integrales en el primer nivel de atención. Material y Métodos: El trabajo se enmarcó dentro del paradigma post positivista con un enfoque Cualitativo y método de estudio de caso; realizado el 2009 en una Micro red de Servicios de Salud. La técnica seleccionada para obtener la información fue entrevista a profundidad. Los informantes fueron 4 enfermeras con más de 2 años de servicios independientemente de su condición laboral. La muestra se obtuvo por saturación y redundancia. La interpretación se realizó comparando las opiniones de los informantes mediante el análisis de contenido. Los criterios éticos y de rigor científico fueron contemplados a largo de la investigación Resultados: Los hallazgos develaron cuatro categorías: "Objetivando la necesidad de integrar en sus cuidados a la persona como ser multidimensional", "Experimentando dificultades y obstáculos para el cuidado integral a la persona en el primer nivel de atención", "Implementando estrategias para el cuidado integral en el primer nivel de atención" y "Priorizando la prevención y promoción en el cuidado integral a las personas". Consideraciones finales: La experiencia de las enfermeras en el primer nivel de atención se centra en el cuidado que brinda principalmente a la persona, siendo necesario tener una visión multidimensional de ésta, ante las dificultades encontradas para brindar cuidados integrales a la persona, la enfermera implementa estrategias como persuasión, confianza alcanzada a través de las visitas

\footnotetext{
${ }^{1}$ Licenciada en Enfermería. Enfermera con trabajo independiente, Chiclayo, Perú. Email: rmorales@gmail.com

${ }^{2}$ Magíster en Gerencia de Servicios de Salud, enfermera del Hospital Regional Lambayeque- Profesora de la Escuela de Enfermería en la Universidad Católica Santo Toribio de Mogrovejo, Chiclayo, Perú. Email: Imuro@gmail.com
} 
domiciliarias, y busca apoyo en la misma comunidad, a través de la formación de los promotores de salud.

Experiences of nurses in providing comprehensive care in the first level of care

\section{ABSTRACT}

Keywords:

Nurses

Experiences

Comprehensive care

First level of attention
The purpose was to describe and analyze the experiences of nurses to provide comprehensive care in the first level of attention. Material and methods: The work was framed in the postpositivist paradigm with a qualitative approach and method of study, carried out in 2009 in a Micronet and health-service. The technique chosen to obtain information was interview in depth. The informants were four nurses with more that two years of irrespective of employment status. The sample was obtain by saturation and redundancy. The interpretation was performed by comparing the views of informants by analyzing content. the criterion ethical and scientific rigor were referred to throughout the investigation. Results: The findings revealed four categories: Aiming need to integrate in their care to the person as a multidimensional, Experiencing difficulties and obstacles for comprehensive health care to the person at the primary care level. Implementing strategies to integrate care in the primary care level, and prioritizing prevention and promotion comprehensive care of people. Final considerations: The experience of nurses focus in the first level care, it focuses mainly on providing care to the person, needed to have a multidimensional vision, given the difficulties in provide comprehensive care to the person, the nurse implements strategies as persuasion, confidence achieved through visits home, and find support in the community, through the training of health workers.

\section{Introducción}

A nivel de Latinoamérica, las enfermeras comunitarias asumen un rol protagónico en el sector salud de cada país, principalmente en el primer nivel de atención'. En nuestro país, el profesional de enfermería, en razón a sus competencias y experiencias, destaca como personal calificado e imprescindible en el trabajo con la comunidad, reflejándose en su respuesta de manera integral a la demanda de cuidados de la persona, familia y comunidad, tanto en cantidad como en calidad y en correspondencia con los múltiples problemas que presenta la sociedad peruana. $^{2}$

En el 2006 la disponibilidad de profesionales de enfermería, por cada 10000 habitantes de nuestro país era de $8.1^{3}$, sin embargo, es todavía insuficiente en relación con la creciente demanda de servicios de salud de la población.

La región Lambayeque cuenta con una población de 1'149 881 habitantes y por cada 10000 se cuenta con 2 a 3 enfermeras distribuidas en 164 establecimientos de salud $^{4}$, quienes realizan 
múltiples funciones al interior de los establecimientos de salud y en la comunidad

La Red Ferreñafe tiene 4 Micro Redes de Servicios de Salud, y la Micro Red Ferreñafe cuenta con 14 enfermeras y 7 establecimientos de salud para atender a una población de 98947 habitantes ${ }^{4}$. Al interior de dichos recintos, la enfermera realiza múltiples funciones durante la atención directa a las personas en los programas de atención por etapas de vida. La observamos cuidando a las comunidades de su jurisdicción, priorizando a la más necesitada de acuerdo a su vulnerabilidad, elaborando y ejecutando planes de intervención con énfasis en la prevención y promoción de la salud y buscando la participación activa de los actores sociales, que en su mayoría no se cumplen por la falta de personal, debido que en cada establecimiento de salud existe una enfermera que desempeña actividades intra y extramurales. Sumado a esto la inseguridad en las comunidades.

Ante esta problemática, se planteó investigar cuáles son las experiencias de las enfermeras al brindar cuidados integrales en el primer nivel de atención - Micro Red de Servicios de Salud Ferreñafe, en el 2009. El objeto de investigación fue las experiencias de las enfermeras al brindar cuidados integrales en el primer nivel de atención; y el objetivo su descripción y análisis.

Esta investigación ha permitido rescatar el valor trascendental de los cuidados de enfermería en el primer nivel de atención, conociendo mucho más de cerca la dinámica en la cual se desenvuelven.

Ante la ausencia de trabajos de investigación que den cuenta de este hecho tan importante, esta investigación aporta nuevos conocimientos para la práctica comunitaria inmersa en un sistema de salud, que actualmente presenta retos laborales y económicos muy importantes para el ejercicio de la profesión.

\section{Metodología}

El trabajo se enmarcó en el paradigma de estudio de caso, así mismo se contemplaron las post positivista con un enfoque cualitativo y método Los sujetos en estudio fueron 4 enfermeras del primer nivel de atención de con más de dos años de servicios, no se tuvo en cuenta su condición laboral. El escenario de investigación fue la Micro tres fases y los principios que rigen su desarrollo ${ }^{5}$. Red de Servicios de Salud Ferreñafe con una población asignada de 98947 habitantes, 7 establecimientos de salud: Centro de Salud de Ferreñafe, Pueblo Nuevo, Mesones Muro, Señor de la Justicia, Picsi, Puesto de Salud de Capote y Las Lomas, y 14 enfermeras cuyo desempeño destaca por la multifuncionalidad.

La técnica seleccionada para obtener la información fue la entrevista abierta a profundidad. La interpretación se realizó comparando las opiniones de los informantes mediante análisis de contenido temático y del discurso.

\section{Resultados, análisis y discusión}

Resultado del análisis de los datos de esta investigación emergieron las siguientes categorías:

\section{Objetivando la necesidad de integrar en sus cuidados a la persona como un ser multidimensional.}

Las informantes dejan entrever que el punto de partida para brindar cuidados integrales de salud es objetivar a la persona como un ser biosicosocial.

Tal como se ve reflejado en los siguientes discursos:

“...el cuidado es integral, tiene que ver con toda las dimensiones de la persona, es decir, evaluar el 
aspecto biológico, psicológico, social, y espiritual..." (LUNITA).

“...la persona es un ser cambiante, es un mundo diferente que viene con tantas cosas, como por ejemplo su diversidad cultural, costumbres arraigadas y no son fáciles de llevar..." (SOL).

La comprensión del hombre como un ser multidimensional implica la existencia de una relación de dependencia e influencia mutuas entre las distintas partes componentes de la persona, de tal forma que cualquier modificación en una de estas partes conlleva necesariamente a una modificación en las restantes ${ }^{6}$. Por su parte, el modelo de atención integral de nuestro país en su principio de integralidad, hace énfasis en la multidimensionalidad de la persona, como seres biopsicosociales, y además la considera inmersa en un sistema de relaciones políticas, sociales, culturales y eco-biológicas 7 . por ser factores que repercuten en la salud de los grupos humanos.

Para brindar un cuidado integral a la persona, las enfermeras del primer nivel de atención desarrollan diversas actividades intra $y$ extramurales, y en este quehacer a diario enfrentan dificultades de orden logístico y de accesibilidad, escasez de recurso humano y las diferentes costumbres que tiene cada persona para el cuidado de su salud, surge la segunda categoría.

\section{Experimentando dificultades y obstáculos para el cuidado integral a la persona en el primer nivel de atención.}

En el primer nivel de atención las enfermeras enfrentan dificultades de tipo logístico y de accesibilidad geográfica, por ejemplo, para realizar visitas domiciliarias no se cuenta con movilidad, sobre todo, para sitios alejados, corriendo el riesgo de ser agredidos. Por falta tiempo la atención se reduce a la demanda intramural. Tal como se aprecia en el siguiente discurso:

"...Para brindar los cuidados extramurales, tenemos deficiencias con la movilidad cuando salimos a realizar visitas. Otra dificultad que tenemos es lajanía de las zonas donde viven. Tenemos población para ir a visitar, pero no es fácil llegar porque no tenemos movilidad..." (LUNITA).

Cuando la enfermera sale de las cuatro paredes de los centros de salud y se inserta en el mundo real de los ciudadanos o personas cuidadas, se encuentran también con miserias mayores a las imaginables: calles donde todos se sienten inseguros, suciedad, marginación, e incluso el riesgo de ser agredidos por la sociedad. Se suma a esto, la lenta zonificación de la atención primaria que, sobre todo, en el medio rural puede suponer distancias muy grandes, lo que extramurales; ya que la distancia entre los domicilios dificulta aún más la realización de las actividades y el centro de referencia marcará un determinado ritmo $^{8}$. El contexto socioeconómico de la persona cuidada es una realidad que la enfermera enfrenta en modificar para mejorar la salud y la calidad de vida su quehacer diario, y que muchas veces debe de las personas.

Otra dificultad que se observa en el primer nivel de atención, es el recurso humano insuficiente, problemática de salud existente desde décadas atrás, a pesar de que las enfermeras son actores primordiales en el trabajo de toda organización de salud y son quienes dedican la mayor parte de su tiempo a la población. Al no contar con recurso humano suficiente, las enfermeras se ven obligadas a delegar algunas actividades al personal de apoyo (técnicos de enfermería), lo cual no quiere decir que tiene menos obligaciones, por el contrario debe asumir la responsabilidad de la supervisión del subalterno. Tal como se aprecia en el siguiente discurso: 
“...En cuanto al recurso humano también es una dificultad porque se necesitan más enfermeras para poder abastecernos con los cuidados que damos tanto intra como extramurales, porque hay solo una enfermera, y por ejemplo para campaña de vacunación hay déficit de personal enfermero ahí quien más nos apoyan son los técnicos..." (SOL).

La problemática de los Recursos Humanos en Salud (RHUS) acontece no solo en nuestro contexto sino a nivel mundial, al respecto la OPS afirma que los procesos de reforma de los sistemas de salud en nuestra región, (refiriéndose a Latinoamérica) en las últimas décadas, dejaron por fuera el tema de los recursos humanos en salud. Concentrándose en los problemas de infraestructura, financiamiento, separación de funciones, descentralización, los recursos humanos fueron concebidos como un conjunto de competencias y un gasto excesivo, y fue la agenda de la precarización del empleo y los ejercicios de racionalización de las instituciones públicas, la comúnmente aplicada a lo largo del continente 9.

Otra de las dificultades para el cuidado en el primer nivel de atención es el aspecto cultural, ya que el sujeto de atención en enfermería es la persona, la familia y la comunidad; siendo la familia el núcleo generador de hábitos, por lo que adquiere gran importancia en el cuidado de la salud de sus miembros. Tal como se aprecia en el siguiente discurso:

"...Dentro de los cuidados brindados a las personas, están sus aspectos culturales, y que hay que tomarlos en cuenta, esto dependiendo si es que no hace daño a su salud, de cierta manera se les deja, pero hay que ir educando, hacer visitas domiciliarias y que estas sean más continuas para que ellos entiendan de que hay cositas que pueden perjudicar su salud $y$ poco a poco vayan entendiendo $y$ dejando un poco de lado costumbres que pueden perjudicar su salud..." (ESTRELLA).
El ciudadano sabe que tiene su propia valoración de la salud. Unas veces se equivoca, pero no transformará su actitud simplemente porque el personal de salud le diga que lo debe hacer8. Según Mariner, la enfermera como profesional que cuida a las personas debe respetar sus valores, creencias, entorno, lenguaje10; hay que comprender su mundo y desde ahí ir transformándolo, teniendo en cuenta no solo la transformación de los conocimientos, sino también las barreras que el individuo pone a nuevas actitudes, la lucha entre la tradición, lo aprendido por sus padres y lo que se le va a enseñar8. La enfermera del primer nivel de atención valora y comprende las costumbres que posee cada persona para su autocuidado rescata los cuidados positivos y utiliza la educación sanitaria, para conseguir que la persona, familia y la comunidad adquieran o mantengan hábitos saludables.

Al existir dificultades que obstaculizan el desarrollo de la enfermería en el primer nivel de atención, es que las enfermeras entrevistadas desarrollan estrategias que permitan brindar cuidados de manera integral a la persona; tales como, conocer detalladamente a la población, -en la que debe trabajar sus costumbres, valores y creencias-; comprender su mundo y desde allí ir transformándolo, hecho que da lugar a la tercera categoría:

\section{Implementando estrategias para el cuidado integral en el primer nivel de atención.}

Una de las estrategias eficaces expresada por los profesionales de enfermería es la persuasión. Según sus experiencias, es utilizada para convencer a las madres sobre la importancia de las vacunas y hacer que participe voluntariamente del proceso de inmunización de su hijo. Tal como se aprecia en el siguiente discurso:

“...Gracias a estas visitas uno se va ganando la confianza de las personas y muchos de ellos llegan a comprender la importancia de los cuidados como 
por ejemplo de las vacunas. Dejamos también que la madre participe cuando llega al centro de salud con su niño para la vacuna, es decir, se le explica a la madre qué es lo que va a recibir a su niño, qué vacuna le estamos aplicando, contra qué lo estamos protegiendo $y$ de esta manera vamos concientizando..." (SOL).

La persuasión es una actividad de comunicación humana diseñada para influir en otro con el fin de modificar sus actitudes o alterar sus conductas mediante argumentos, razonamientos 0 exhortaciones. Las enfermeras emplean la persuasión, como estrategia o técnica vital para alcanzar las metas de atención al paciente. Tres aspectos son cruciales para una comunicación persuasiva: compromiso, imaginación y confianza ${ }^{11}$.

En el primer nivel de atención la enfermera realiza visitas domiciliarias con el fin de que las personas mantengan estilos de vida saludables, como parte del Programa de familia y vivienda saludable, teniendo en cuenta que las personas en general viven en familia y es allí donde nacen, aprenden conductas de salud, enferman, reciben cuidados y en muchas ocasiones, mueren. El siguiente discurso así lo evidencia:

\section{“...Para realizar el Programa de familia y vivienda} saludable se hacen visitas domiciliarias, a familias de riesgo, o sea se va se les hace una visita para ver en qué condiciones vive y qué tipo de riesgo mayores tienen..." "...Con esas familias se identifica el problema y se les orienta con charlas educativas se vuelve a visitar, visitas tras visitas para poder ver si ha habido cambios en su comportamiento..." (LUNITA).

La implementación del Programa de familia y vivienda saludable tiene fases como: sensibilización; planificación, ejecución ${ }^{5}$. En este proceso las enfermeras del primer nivel de atención han tenido la oportunidad de reforzar las habilidades adquiridas desde su formación profesional como interacción social, empatía y comunicación asertiva con la persona y su familia durante el cuidado brindado; son el recurso humano del equipo de salud con mayor acercamiento social con el usuario del servicio, hecho que ha contribuido a ganar su confianza, y le ha permitido relacionarse mejor con las personas y lograr los objetivos planteados en el cuidado.

Otra de las estrategias referidas por las enfermeras del primer nivel de atención es la formación de promotores de salud, tal como se aprecia en el siguiente discurso:

“...Tenemos 4 promotores de salud, que son nuestro gran apoyo; porque nos ayudan a identificar los problemas de su comunidad, ellos tienen un empadronamiento de todos los niños; porque, por ejemplo, si yo me voy a una jornada a tal sector, entonces, ellos te informan cuántos niños hay para vacunas de un año, de dos de cuatro y seis meses..." (ESTRELLA).

La formación de promotores es una estrategia utilizada para trabajar con la persona, familia y la comunidad, porque permite obtener una mejor respuesta de la comunidad y evitar duplicar esfuerzos. Además, asegura la continuidad de los procesos, pero lo más importante es que fomenta la solidaridad entre los miembros y favorece las relaciones positivas con la comunidad, trabajando acercarse a la realidad en que viven, logrando una por la salud de ellos mismos, lo cual permite distribución lógica del trabajo en enfermería ${ }^{12}$.

Hoy en día es indiscutible que existen procedimientos eficaces de prevención y promoción de la salud que disminuyen la morbimortalidad de algunas patologías prevalentes; la prevención de la enfermedad desarrolla acciones que proceden del sector sanitario, la promoción de la salud realiza acciones para mejorar la salud y proceden de la comunidad, así surge esta cuarta categoría: 
Priorizando la prevención y promoción en el cuidado integral a las personas en el primer nivel de atención.

Según las entrevistadas, el trabajo en el primer nivel de atención involucra acciones de salud de tipo preventivo- promocional dirigidas a la persona en sus diferentes etapas de su ciclo vital, realizando prevención en problemas de salud como de EDAS e IRAS principalmente en niños, con el único fin de mejorar la salud. Como se refleja en el siguiente discurso:

“...Los cuidados principales que se brindan al paciente, son el cuidado preventivo - promocional al niño, a la madre se le trata de englobar todo...los cuidados que damos son preventivos promocionales, como por ejemplo: en cada una de las etapas..." (UNIVERSO).

En el primer nivel de atención se atiende el 70\% a $80 \%$ de la demanda del sistema de salud. Aquí la severidad de los problemas de salud plantea una atención de baja complejidad con una oferta de gran tamaño y con menor especialización y tecnificación de sus recursos.

En este nivel se desarrollan principalmente actividades de promoción y protección específica, diagnóstico precoz y tratamiento oportuno de las necesidades de salud más frecuentes?.

Los programas de salud son la vía por la que el sistema de salud cuida a los ciudadanos, controla la salud en las diferentes etapas, les provee la información necesaria para mejorar su salud o sobrellevar su enfermedad, les facilita los medios para detectarla precozmente, les enseña a convivir con sus enfermedades crónicas ${ }^{12}$. Sánchez agrega que promover, mantener la salud, prevenir la enfermedad y ayudar a mejorar la calidad de vida de las personas son el objetivo central de la atención primaria13. Que adquiere mayor protagonismo en el primer nivel de atención ámbito en el que la enfermera hasta hoy lidera el quehacer.

\section{Consideraciones finales}

Las experiencias de las enfermeras en el primer nivel de atención se centran en el cuidado que brinda principalmente a la persona, siendo necesario tener una visión multidimensional de ella.

El profesional de enfermería que trabaja en el primer nivel de atención experimenta día a día dificultades de tipo logístico y de accesibilidad geográfica, escasez de recurso humano en enfermería y el aspecto cultural de las personas cuidadas, lo que dificulta la realización de las actividades extramurales planificadas por las enfermeras, esto según su percepción para aspectos político-contextuales que caracterizan el trabajo en el Ministerio de Salud.

Ante las dificultades encontradas para brindar cuidados integrales a la persona en el primer nivel de atención, la enfermera implementa estrategias obtenidas día a día en respuesta a las necesidades de la persona cuidada, tales como persuasión, confianza alcanzada a través de las visitas domiciliarias, y buscar apoyo en la misma comunidad, a través de la formación de los promotores de salud, que permitan alcanzar los objetivos planteados.

La experiencia adquirida por las enfermeras en el primer nivel de atención se centra referentemente en actividades preventivo-promocionales; direccionadas a ayudar a las personas a mejorar su salud y por ende, su calidad de vida, a través de programas de salud que contribuyen a que el sistema de salud proteja a los ciudadanos.

Se recomienda a las instituciones que forman profesionales de enfermería, fortalecer la práctica comunitaria en la formación preprofesional rescatando el valor trascendental de los cuidados de enfermería en el primer nivel de atención. Considerando el liderazgo, la capacidad de gestión del cuidado, saber concertar en busca de alianzas estratégicas, estos aspectos son básicos para 
enfrentar ciertas limitaciones propias del sistema y de la idiosincrasia de la población.

\section{Bibliografía}

1. Bustamante S. El proceso de Atención de Enfermería con Familias. Situación de la Enfermería Comunitaria en el Perú y América Latina. Disponible en: http://neclayc.galeon.com/ articulo2emfcom.htm. 1996.

2. Colegio de Enfermeros del Perú. Programa de Educación permanente en Enfermería. Consejo Nacional-Certificación Profesional. Modulo I. Cuidado de Enfermería en la Salud Comunitaria. Lima-Perú. 2008.

3. Dirección Regional de Salud Lambayeque. Análisis de Situación de Salud. Ministerio de salud. Disponible en: http://siga. regionlambayeque.gob.pe. 2008

4. Ministerio de Salud. Oficina estadística. Red de Servicios de Salud. Ferreñafe- MINSA. Disponible en: http://www.minsa.gob.pe/ubilambayeque. 2008.

5. Menga, Ludke. Pesquisa en Educacao: Abordagens Cualitativos. Andre - Sao Paulo. EPU. Editora Pedagógica e Universitaria. 1986.
6. Prado M. Fundamentos teóricos y cuidados básicos de enfermería. Primera edición. 1996.

7. Ministerio de Salud (MINSA). Modelo de Atención de Salud. 2008.

8. Nardiz, Antón. De Médicos a Enfermeros de Comunidad. Madrid. Primera edición. 1989.

9. Jaramillo M. Estudio sobre los Recursos Humanos en Salud en Perú: Gestión, Distribución, Normatividad, Regulación, Condiciones laborales y salariales y Formación. Grupo de Análisis para el Desarrollo. GRADE. Disponible en: http: / / www.grade.org.pe/download/docs/Inform e\%20Final\%20RRHH\%20Salud\%20GRADE.pdf. 2006

10. Marriner, Tommy A, Raile M. Modelos y Teorías de Enfermería. 4ta edición. Editorial Harcourt Brace. España; 2002.

11. Monserrat, Roger/CAJA, Carmen/UBEDA, Bonet. Enfermería Comunitaria. Instituto MONSA de Ediciones. $1^{\circ}$ Edición. 2007.

12. Gaillour Ferradas, Álvaro. Proyecto salud y nutrición básica. Manual del Promotor y Promotora de Salud. MINSA. Lima - Perú. $1^{\circ}$ Edición. 2001.

13. Sánchez Moreno. Actuación de Enfermería Comunitaria y Sistemas y Programas de Salud. Madrid - España: McGraw Interamericana. Editorial S.A.; 2000. 